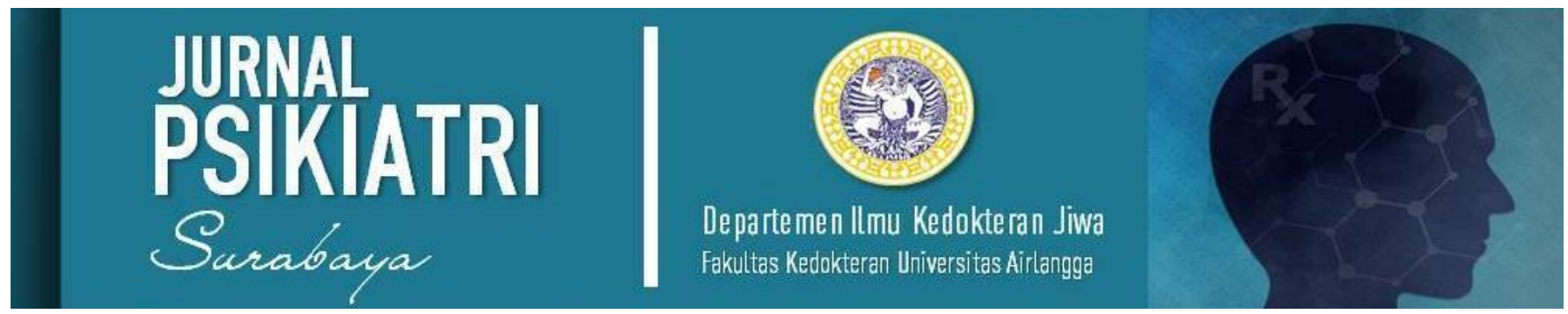

Case Report

\title{
Sucide Attempt in Acute Psychoic Conditions from Biopsychosicial Management Review
}

\author{
Meilaniwati Sarfa $^{1,2}$, Melati Wahyurini ${ }^{1,2}$, Era Catur Prasetya ${ }^{3}$ (i) \\ ${ }^{1}$ Department of Psychiatry, Faculty of Medicine, Universitas Airlangga, Surabaya, Indonesia \\ ${ }^{2}$ Dr. Soetomo General Hospital, Surabaya, Indonesia \\ ${ }^{3}$ Department of Psychiatry, Faculty of Medicine, Universitas Muhammadiyah Surabaya, Indonesia
}

\section{OPEN $\bigcirc$ ACCESS}

\section{ARTICLE INFO}

Received: August 5, 2020

Revised: September 14, 2020

Accepted: September 21, 2020

Published: May 31, 2021

*) Corresponding author:

E-mail:dr.catur@gmail.com

Keywords:

acute and transient psychotic disorders

suicide attempt

management of a

biopsychosocial model

This is an open access article under the CC BY-SA license

(https://creativecommons.org/lic enses/by-sa/4.0/)

Abstract
Acute psychotic and transient disorders have annually increased, especially in
developing countries. The highest prevalence for acute Psychotic disorders is currently
in three developing countries, namely Ibadan, Nigeria, and India. Reported the most
causes by psychosocial factors and biological factors. Acute and Transient Psychotic
disorders have an annual incidence rate of about $3.9 \%$ to $9.6 \%$ of the 100.000
population. The reported prevalence range from $10 \%$ to $50 \%$ mostly in the first year.
We aim to report a case of Acute and Transient Psychotic Disorders accompanied by
suicide attempts to increase cases so that psychiatrists should be able to make a
diagnosis quickly and precisely because it is included in the emergency psychiatric.
Acute and Transient Psychotic Disorders often cause symptoms in the form of acts of
self - harm or others, in the form of committing suicide, which is a very important
social phenomenon and requires attention not only from a psychiatrist but also the
general public. The phenomenon of suicide has spread to almost all parts of the world,
both in countries with advanced technology and in developing countries. Integrated
management of this case is clinically oriented to a biopsychosocial model that is used
as a basic principle in the clinical practice of a doctor in building relationships with
patients. In this case, we reported a 24 - year - old male, the first attack, occurring
within one week, and accompanied by suicidal thoughts. So it is necessary to take a
biopsychosocial approach that aims for comprehensive and sustainable interventions.

Cite this as:Sarfa, M., Wahyurini, M., Prasetya, E. C. "Sucide Attempt in Acute Psychoic Conditions from Biopsychosicial Management Review”. Jurnal Psikiatri Surabaya, vol. 10, no. 1, pp. 40-45, 2021, doi: 10.20473/jps.v10i1.21191. 


\section{INTRODUCTION}

Acute and transient psychotic disorders can be seen from diagnostic criteria in the form of acute onset, short duration, and recovery occur within 2-3 months [1]. The most common cause that we encounter, is due to experiencing a life event that is full of pressure, especially for people who are vulnerable to psychological problems. In some studies that focus on this disorder, which involves in terms of domain aspects of clinical psychopathology that is used as an interesting key variable in terms of determining a risk assessment, seen from the onset and also from the journey of mental illness itself, especially in the productive age (young age), especially those that have genetic factors [2].

The psychopathology domain can be used as a sign of symptoms that exist in this disorder and can be used in terms of distinguishing other psychotic disorders [3]. If there are risk factors with the onset of the first disorder, early age, male sex, and more extended hospital stays, this will increase the risk of future schizophrenia. Several national studies in the UK and Denmark have reported around 1,0000 cases annually with the range of 3.9 to $9.6 \%$, while prevalence studies are reported to range from $5.9 \%$ to $20 \%$ in clinical-based hospitals [4].

Suicidal behavior is reported to be quite high at around $36-55 \%$, especially in the acute polymorphic phase, which is usually with unstable mood [5]. In 2017, the United States amount to as high as 100-200 attempts per suicide in adolescents 15-24 years old [6]. Onset Younger has a high risk of attempting suicide. Patients with depressive symptoms of comorbidity have a family history of suicide including being at high risk who need special attention [7]. A person who has the risk of endangering himself or endangering others is an important condition in this case. According to Dr. George Engel, 1980 in his book on Biopsychosocial Formulations, in terms of risk assessment, doctors must know terms of knowing biological, psychological, and social risk factors. So it will be easier in terms of collecting data to assess risk factors that exist in patients. Fostering good relationships with patients, digging as much data as possible can be obtained from interviews directly with patients or from families so that practical approaches using biopsychosocial formulations can be fulfilled [8]. It is also inseparable from our knowledge and understanding of the psychodynamic formulations of patients, starting from the difficulties they face in everyday life, starting from a history of growth and development, parenting, childhood experiences to adulthood [9].
One of the theories of children's mental development "Sigmund Freud", discusses the main development patterns as the basic capital of individuals who focus on the theme of psychoanalysis / psychosexual starting from the age of 0-1 years, known as the oral phase, wherein this phase infants need a good stimulus, especially from his mother. Ages 1-3 years are called the anal phase, ages 3-6 years, are called the phallic/oedipal phase, ages 6-11 years, are called the latent phase, and ages 11-18 years, are called the genital phase. As a doctor, we must be able to explore the difficulties that are being experienced by patients, build trust so that patients want to tell about what he is feeling right now, maybe in terms of difficulties to control themselves, difficulties in terms of selfesteem, or difficulties in building relationships with people other. This theory was created to overcome psychological vulnerability for those who experienced trauma during childhood as we are familiar with "conflict". If the conflict is not resolved properly can have an impact on the person in the future, coupled with the journey of life more and more pressure, this could become a new stressor. Other developmental theories that are also important in children's mental development, namely Erick Ericson's developmental theory, where this theory considers psychosocial problems that occur at certain times (or stages) in a patient's life, starting from trust versus mistrust (birth to about 18 months), autonomy versus shame and doubt (about 18 months to about 3 years), initiative versus guilt (about 3 years to about 5 years), industry versus inferiority (about 5 years to about 13 years), identity versus role confusion (about 13 years to about 21 years), intimacy versus isolation (about 21 years to about 40 years), generativity versus stagnation (about 40 years to about 60 years), integrity versus despair (about 60 years to death) [10]. Both of these theories are needed in management using biopsychosocial formulations, especially those related to a person's psychological factors [9].

Diagnostic and Statistical Manual of Mental Disorders, Fifth Edition (DSM 5) published by the American Psychiatric Association (APA) in 2013, and divides the Working Group on Psychotic Disorders Classification (WGPD), which is paired with the World Health Organization (WHO), in hopes of produced something new about the chapter on schizophrenia and other primary psychotics. In some research for ongoing acute and transient psychotic disorders themselves discuss different domains ranging from clinical studies to studying neurobiology, genetics, nosology, neuroimaging, neurophysiology, biochemistry, and neuropsychology [4]. 
JPS. Volume 10 No 1. May 2021 / Negative Symptoms Management in Schizophrenia

Therefore, psychotic is considered as a collection of symptoms, where someone who has a mental disorder, affective, ability to recognize reality, how to communicate, and relate to other people is disturbed [11].

Some studies are mostly related to social and cultural factors. Most reportedly came from developing countries. The highest prevalence in migrant populations, where they move from their original area to another region, such conditions require adaptation in new places, so that such conditions may make them more and more under pressure so that they can become new stressors. This temporary acute psychotic disorder has a consistent state of polymorphic type, where there are various symptoms (such as temporary, delusional, mood instability, agitation behavior, and accompanied by fluctuating anxiety symptoms, and some negative symptoms) which we can distinguish from the symptoms of schizophrenia or schizoaffective [4].

Acute and transient psychotic disorders prevalence was reported for about 104 cases and varies around 5.8\% to $19.0 \%$ with the greatest number of events in low and middle-income countries, where the location is reported to have an earlier age earlier than in high-income countries. Gender-based incidents are more common in women and the appearance of more than two subtypes with symptoms such as acute schizophrenia [12]. We report a case report of attempted suicide caused by acute and transient psychotic disorders with a biopsychosocial model approach management.

\section{CASE REPORTED}

A man 24-year-old was brought by the family to the emergency department of Dr. Soetomo hospital, with the chief complaint of wandering about his job at that he has been felt for four days ago. He looks older than his age, lean, Javanese, working as a parking supervisor in a private company, already married, and has two children. The patient feels his friends at the office do not like him, and feel his mind can be read and known by others. Also, patients complain of difficulty sleeping, especially at night, only sleep about 2 to 3 hours a day, Emotions are often unstable in the form of anger for no apparent reason. Be not excited when going to the office. The patient also complained of hearing voices from both ears, like male voices, many people, that mocked him by saying he was not a bad person, many who did not like the patient. The sound made it so uncomfortable that the patient banged his head several times on the wall of the office room, hoping that the sounds would disappear from his hearing.

According to the wife, the patient has begun to experience behavioral changes for one week before submitted to the hospital. Frequently speaking wandering about work issues, feel uncomfortable at the office because many colleagues seem to be jealous of his current position at the office. And the problem of the patient's discomfort with their superiors. Besides, patients also feel scared and feel guilty for lending money to one of the office friends using cash belonging to the office. This is all according to the wife that keeps the patient in mind. Patients who have not worked for one year in this company have been trusted to be parking supervisors and hold finance at the office. But the wife once tried to confirm this problem directly to the office by asking many colleagues from the office and they all denied that no one felt jealous of the patient. Besides, other complaints from this patient according to his wife are that he often smiles, his uncontrolled emotions, that is angry for no apparent reason, more smoking and indeed the patient has difficulty falling asleep until the new body can sleep. This week the patient has felt lazy to go to the office, eating and drinking decreased slightly. The patient also tells his wife about the voices that are heard suddenly when he is not doing activities, such as sitting in an office chair. The sounds made him uncomfortable which make so the patient does banging his head against the wall several times. The patient also once again attempted suicide, suddenly climbed onto the roof of the house to jump down, but when it did not happen because it was assisted by relatives who were finally able to calm down patients to get down from the roof of the house.

During this time according to the wife, the patient had never been treated and did not have physical pain. Active smoker patients, one pack a day, and drink one to two glasses of coffee a day. There is a history of alcohol consumption, the last drink about 2 months ago when there was an event staying up late at the office, but patients rarely drink alcohol. For family history of mental disorders, there is a grandmother on the part of the father and the first sibling having a mental disorder. According to his wife, patients before illness are known as good people, tend to be quiet, if there are problems with the patient there are some stories of the wife told directly to find a solution, even if there is a difference in understanding with the patient's wife usually goes to her mother's house. Patients also rarely talk or communicate with their families or other people around them, he only talks if necessary only and never tell the problem to others. The patient also rarely hang out, rarely socialize or participate in activities outside, spend more time at work, when the holidays are spent at home playing guitar or playing mobile phones, and do not have close friends. The patient also rarely participate in social activities 
in the home environment.

Patients treated in psychiatric wards, on physical and neurological examinations within normal limits. Continued with laboratory tests, the results were also normal and toxicological tests were all negative. For the Positive and Negative Scale Score (PANSS) at admission, positive scale 22, negative scale 27, general psychopathology scale 37 , and repeated measurements of the seventh day PANSS Score decreased to positive scale 14 , negative scale 16 , general psychopathology scale 23. Psychopharmacology was given 2 x $2 \mathrm{mg}$ of risperidone tablets, oral, morning, night, and clozapine tablets 1x $25 \mathrm{mg}$ peroral, night. During treatment the patient has improved, symptoms of auditory hallucinations are not obtained and the desire to commit suicide is also absent. Following the existing activities in the ward such as occupational therapy, and for eight days the patient was treated with conditions getting better so that he was allowed to go home. Psychopharmacology is continued and is provided with education both to the patient himself and his family.

\section{DISCUSSION}

In this case, as an initial process of learning students can begin by using a biopsychosocial approach. Where according to Dr. George Engel, 1980. The symptoms can help us formulate that appear in patients, facilitate understanding of the origin of the difficulties experienced by patients, and enable us in developing a comprehensive care management plan by knowing the symptoms and diagnostic criteria for mental disorders and we must also have an understanding capital of biological, psychological and social theories. This biopsychological social method is divided into seven formulations, namely: biological formulation, psychological formulation, social formulation, differential diagnosis, risk assessment, biopsychosocial treatment plan, and prognosis. So that we can practice it in the order and continue to practice our abilities in handling psychiatric cases.

In this case, it could be started with the first step, which is to complete the interview that we can get both from the patient himself (autoanamnesa) and the family (heteroanamnesa). After that, we can start on the biological formulation that we can get from demographic data, in the form of the patient's age, sex, ethnic Javanese, history of the disease now with the main complaint of wandering about work, which is felt since one week before entering the hospital. Then for a medical history, we did not found any history of previous illness as well as a history of treatment. The previous history of psychiatric disorder was also absent. History of drug use was denied. We only found a history of alcohol drinking about 2 months ago. In this patient, genetic history was obtained, in which his grandmother of the father and the first brother had a mental disorder. On the physical and neurological examination within normal limits, the psychiatric status examination obtained a general impression of adult male patients, the face looks older than his age, thin-skinned, verbal contact is quite smooth, compliments change, good orientation, mood/dysphoric/adequate effect, the process of thinking is obtained non-realistic, coherent, thought prosecuting, auditory hallucinations grade 5 accompanied by the behavior of suicide attempts, decreased will, psychomotor within normal limits.

In psychological formulations, we can review aspects of cognitive, behavioral, and psychodynamic theories, which will help us understand the nature of vulnerability that can cause patients to think about themselves, their relationships, and their role in the surrounding environment. So we can use psychological formulations. Here we can get the history of the closest family (parents). The focus of the question revolves around the patient's development (psychodynamics), starting from the womb, including the expected child, the prenatal phase, starting from the breastfeeding phase, on his stomach, crawling, sitting, toilet training, talking or walking. educational history ranging from kindergarten, elementary school, junior high school, high school, marriage history, employment history, and others. Here we also need to ask about the role of parents in forming a personality, starting from parenting, instilling trust, and self-confidence, comfort. In this patient, the data obtained were closed personality, did not have good friends if he had any problems he just stayed quiet, his time was spent by working when holidays he was usually staying at home.

For social formulation, we need to assess the social strength and vulnerability of patients to consider social interventions that can reduce stress. Ten categories form the basis of social formulations, namely family problems, friends, social environment, education, employment, housing, income, access to health services, legal issues, and others. Also can not be separated from a cultural, spiritual, and religious assessment. In this case, the problem is related to social formulation in the form of work and social environment problems. 
JPS. Volume 10 No 1. May 2021 / Negative Symptoms Management in Schizophrenia

In terms of differential diagnoses, we first observe clinical signs, onset, there are clear stressors that influence behavioral changes, as well as the presence of clear genetic factors in these patients. To understand the definition of Acute and Temporary Psychotic Disorders and that is a brief psychotic disorder, acute onset, usually appearing suddenly after getting a clear stressor, so that the stress is caused by a sudden and clear state of frustration or conflict from within or from outside, usually also accompanied by a state of anxiety [13]. In Indonesia, the criteria for diagnosis are still using the Third Edition (PPDGJ-III) Guidelines for the Classification and Diagnosis of Mental Disorders, which refers to the International Statistical Classification of Diseases and Related Health Problems 10th Revision [14]:

a. Use a diagnosis sequence that reflects the order of priority given to the main selected characteristics of the disorder. The priority sequence used is acute onset (2 weeks or less, the duration of a real psychotic symptom that disrupts several aspects of daily life and work, but here does not include the prodromal phase where the symptoms are unclear), there is a characteristic syndrome (polymorphic) which means diverse, rapidly changing, or "Schizophrenia-like", the symptoms are typical. There is acute stress (but not always there, so it can be specified again with the code xo: without accompanied by acute stress, $\mathrm{x} 1$ : with accompanying acute stress and prolonged difficulty should not be included as a source of stress in this category, and it is usually unknown how long this disorder will last.

b. There are no disturbances that lead to the Manic Episode (F30.-) or Depressive Episode (F32.) criteria in this group, although there are changes Individual emotional and affective symptoms can be prominent at any time.

c. There are no organic causes, such as head trauma, delirium, or dementia, or intoxication due to alcohol or drug use. In this case, we were able to establish several differential diagnoses obtained from psychiatric status examinations, namely: Mental and Behavioral Disorders due to substance/alcohol use, Episodes of Severe Depression with Psychotic Symptoms.

Furthermore, in terms of risk assessment, it can be asked whether the patient has the risk of endangering himself or others. In this risk assessment, doctors are expected to already understand and have knowledge about biological, psychological, and social risk factors, thus it will be easier for us to conduct a risk assessment. Usually, for risk assessment, this is done after the first data from biological, psychological, and social formulations and differential diagnoses have been taken. Usually, the risk assessment discusses two things namely those related to the potential for self-harm (suicide) and their potential to commit violence against others. In this case, the potential for a suicide attempt was the result of a psychotic symptom experienced by the patient, namely hearing a voice in both ears mocking and ordering to do, thus to reduce this risk, the patient was hospitalized in psychiatric.

For treatment plans in these patients, from the data in the form of laboratory results when treated normal results and also no accompanying physical disease found in these patients, so it is considered for patients to receive atypical antipsychotic drugs by continuing to observe the side effects of the treatment given. Besides that, there are also some assessments that we value in this patient, such as the PANSS Score scale, which is assessed from the beginning of the entry and when several days are treated, the patient experiences a change from the PANSS score towards improving. Suggestions can also be recommended to do other psychometric assessments to determine mood disorders in these patients. According to several studies found suggestions for cognitive therapy, which can reduce the risk of suicide in cases like this. We can start interventions by doing vocational rehabilitation, training social skills, and doing work that patients like to support from feelings of isolation from social and feelings of hopelessness, and reduce stigma against him. All of this is useful in terms of reducing the risk of suicide. Family intervention is also needed, in terms of reducing the risk of suicide. The conclusion can be drawn that such an intervention is necessary in the handling of cases with psychotic disorders [15]. So that the prognosis, in this case, is still good.

Acute and transient psychotic disorders reported about 104 cases about prevalence to vary around $5.8 \%$ to $19.0 \%$ with the greatest number of events in low and middle-income countries, where the location is reported to have an earlier age earlier than in high-income countries. Gender-based incidents are more common in women and the appearance of more than two subtypes with symptoms of symptoms such as acute schizophrenia [12].

\section{CONCLUSION}

Using a biopsychosocial approach to carry out a systematic and comprehensive assessment can help us to formulate the symptoms that appear in a patient and understand the origin of the patient's predicament. Judging from the diagnostic criteria for acute and transient psychotic 
disorders with acute onset, short duration, and recovery period of 2 - 3 months with stressful life events especially prone to psychological problems. Also, it is seen from the risk factors with the onset of the first disorder, early or productive age, gender, and most important genetic factors, which will increase the risk of developing schizophrenia in the future. Suicidal behavior is reported to be quite high, especially in acute conditions.

From a psychological aspect, the family intervention has an important role in supporting and increasing patient confidence. Likewise with social interventions, which play a very important role in reducing stigma in society, thereby restoring self-confidence and continuing daily activities as they were before the illness.

\section{Acknowledgments}

The author would like to thank the subject and his family.

\section{Conflicts of interest}

The author declared no potential conflicts of interest for the research, authorship, and/or publication of this article.

\section{REFERENCES}

[1] F. Biedermann and W. W. Fleischhacker, "Psychotic disorders in DSM-5 and ICD-11," CNS Spectr., vol. 21, no. 4, pp. 349-354, 2016, doi: $10.1017 / \mathrm{S} 1092852916000316$.

[2] J. L. Shah et al., "Clinical psychopathology in youth at familial high risk for psychosis," Early Interv. Psychiatry, vol. 13, no. 2, pp. 297-303, 2019, DOI: 10.1111/eip.12480.

[3] S. Heckers et al., "Structure of the Psychotic Disorders Classification in DSM-5," Focus (Madison)., vol. 14, no. 3, pp. 366-369, 2016, DOI: 10.1176/appi.focus.140307.

[4] S. Malhotra, S. Sahoo, and S. Balachander, "Acute and Transient Psychotic Disorders: Newer Understanding," Curr. Psychiatry Rep., vol. 21, no. 11, pp. 1-11, 2019, DOI: $10.1007 / \mathrm{s} 11920-019-1099-8$.

[5] A. C. Castagnini and P. Fusar-Poli, "Diagnostic validity of ICD-10 acute and transient psychotic disorders and DSM-5 brief psychotic disorder," Eur. Psychiatry, vol. 45, pp. 104-113, 2017, DOI: 10.1016/j.eurpsy.2017.05.028.

[6] S. Bachmann, "Epidemiology of suicide and the psychiatric perspective," Int. J. Environ. Res. Public Health, vol. 15, no. 7, pp. 1-23, 2018, DOI: 10.3390/ijerph15071425.

[7] M. Dong et al., "Prevalence of suicide attempts in bipolar disorder: A systematic review and meta-analysis of observational studies," Epidemiol. Psychiatr. Sci., 2019, DOI: 10.1017/S2045796019000593.

[8] S. Inquiry, R. M. Epstein, and G. E. S. Legacy, "The Biopsychosocial Model 25 Years Later :" pp. 576-582, 2004, DOI: 10.1370/AFM.245.Department.

[9] W. Campbell, The Biopsychosocial formulation manual, A guide fo., no. 1. New York, 2006.

[10] S. benjamin. J, M. Pedro Ruitz, and et al, Kaplan \& Sadock's Synopsis of Psychiatry, Eleventh e. New York, 2014.

[11] S. M. Stahl, Stahl's Essential Psychopharmacology: Neuroscientific Basis and Practical Applications, vol. 4, no. 1. New York, 2013.

[12] M. Z. U. H. Katshu, "Acute transient psychotic disorder precipitated by Brexit vote," BMJ Case Rep., vol. 12, no. 10, pp. 12-14, 2019, DOI: 10.1136/bcr-2019232363.

[13] A. M. Maramis.W.F, Catatan ilmu kedokteran jiwa edisi 2, Kedua. Surabaya, 2009.

[14] R. Maslim, Buku saku Diagnosis Gangguan Jiwa: Rujukan Ringkas dari PPDGJ-III dan DSM 5. Jakarta, 2013.

[15] L. Sher and R. S. Kahn, "Suicide in schizophrenia: An educational overview," Med., vol. 55, no. 7, pp. 1-11, 2019, DOI: 10.3390/medicina55070361. 